\title{
Synthesis of 2,4,6-Trisubstiuted Pyridines by Oxidative Eosin Y Photoredox Catalysis
}

\author{
Rajendra S. Rohokale, ${ }^{\#}$ Burkhard Koenig ${ }^{* \dagger}$ and Dilip D. Dhavale ${ }^{* \#}$ \\ "Department of Chemistry, Savitribai Phule Pune University (formerly University of Pune), \\ Ganeshkhind, Pune-411007. \\ ${ }^{\dagger}$ Institute fuer Organische Chemie, Universitaet Regensburg, Universitatstrasse 31, 93053 \\ Regensburg, Germany \\ E-mail: ddd@chem.unipune.ac.in,Burkhard.Koenig@chemie.uni-regensburg.de
}

\footnotetext{
Page(s)

${ }^{1} \mathrm{H}$ and ${ }^{13} \mathrm{C}$ NMR spectrum of $\mathbf{3 a} \mathrm{S} 2$

${ }^{1} \mathrm{H}$ and ${ }^{13} \mathrm{C}$ NMR spectrum of $\mathbf{3 c} \mathrm{S} 4$

${ }^{1} \mathrm{H}$ and ${ }^{13} \mathrm{C}$ NMR spectrum of $\mathbf{3 e}$ S6

${ }^{1} \mathrm{H}$ and ${ }^{13} \mathrm{C}$ NMR spectrum of $\mathbf{3 h} \mathrm{h} 8$

${ }^{1} \mathrm{H}$ and ${ }^{13} \mathrm{C}$ NMR spectrum of $\mathbf{3 j}$ S10

${ }^{1} \mathrm{H}$ and ${ }^{13} \mathrm{C}$ NMR spectrum of $31 \mathrm{~S} 12$

${ }^{1} \mathrm{H}$ and ${ }^{13} \mathrm{C}$ NMR spectrum of 3n S14

${ }^{1} \mathrm{H}$ and ${ }^{13} \mathrm{C}$ NMR spectrum of $\mathbf{3 p} \mathrm{S} 16$

${ }^{1} \mathrm{H}$ and ${ }^{13} \mathrm{C}$ NMR spectrum of 3 r S18

${ }^{1} \mathrm{H}$ and ${ }^{13} \mathrm{C}$ NMR spectrum of $4 \mathrm{~S} 20$

${ }^{1} \mathrm{H}$ and ${ }^{13} \mathrm{C}$ NMR spectrum of 5 S22
}

\footnotetext{
${ }^{1} \mathrm{H}$ and ${ }^{13} \mathrm{C}$ NMR spectrum of $\mathbf{3 b} \mathrm{S} 3$

${ }^{1} \mathrm{H}$ and ${ }^{13} \mathrm{C}$ NMR spectrum of $\mathbf{3 d} \mathrm{S} 5$

${ }^{1} \mathrm{H}$ and ${ }^{13} \mathrm{C}$ NMR spectrum of $\mathbf{3 f} \mathrm{S} 7$

${ }^{1} \mathrm{H}$ and ${ }^{13} \mathrm{C}$ NMR spectrum of $\mathbf{3 i} \mathrm{S} 9$

${ }^{1} \mathrm{H}$ and ${ }^{13} \mathrm{C}$ NMR spectrum of $\mathbf{3 k} \mathrm{S} 11$

${ }^{1} \mathrm{H}$ and ${ }^{13} \mathrm{C}$ NMR spectrum of $\mathbf{3} \mathbf{m ~ S 1}$

${ }^{1} \mathrm{H}$ and ${ }^{13} \mathrm{C}$ NMR spectrum of $\mathbf{3 o} \mathrm{S} 15$

${ }^{1} \mathrm{H}$ and ${ }^{13} \mathrm{C}$ NMR spectrum of $\mathbf{3 q} \mathrm{S} 17$

${ }^{1} \mathrm{H}$ and ${ }^{13} \mathrm{C}$ NMR spectrum of 3s $\mathrm{S} 19$

${ }^{1} \mathrm{H}$ and ${ }^{13} \mathrm{C}$ NMR spectrum of $\mathbf{3 t} \mathrm{S} 21$

HRMS data of 5 S23
} 

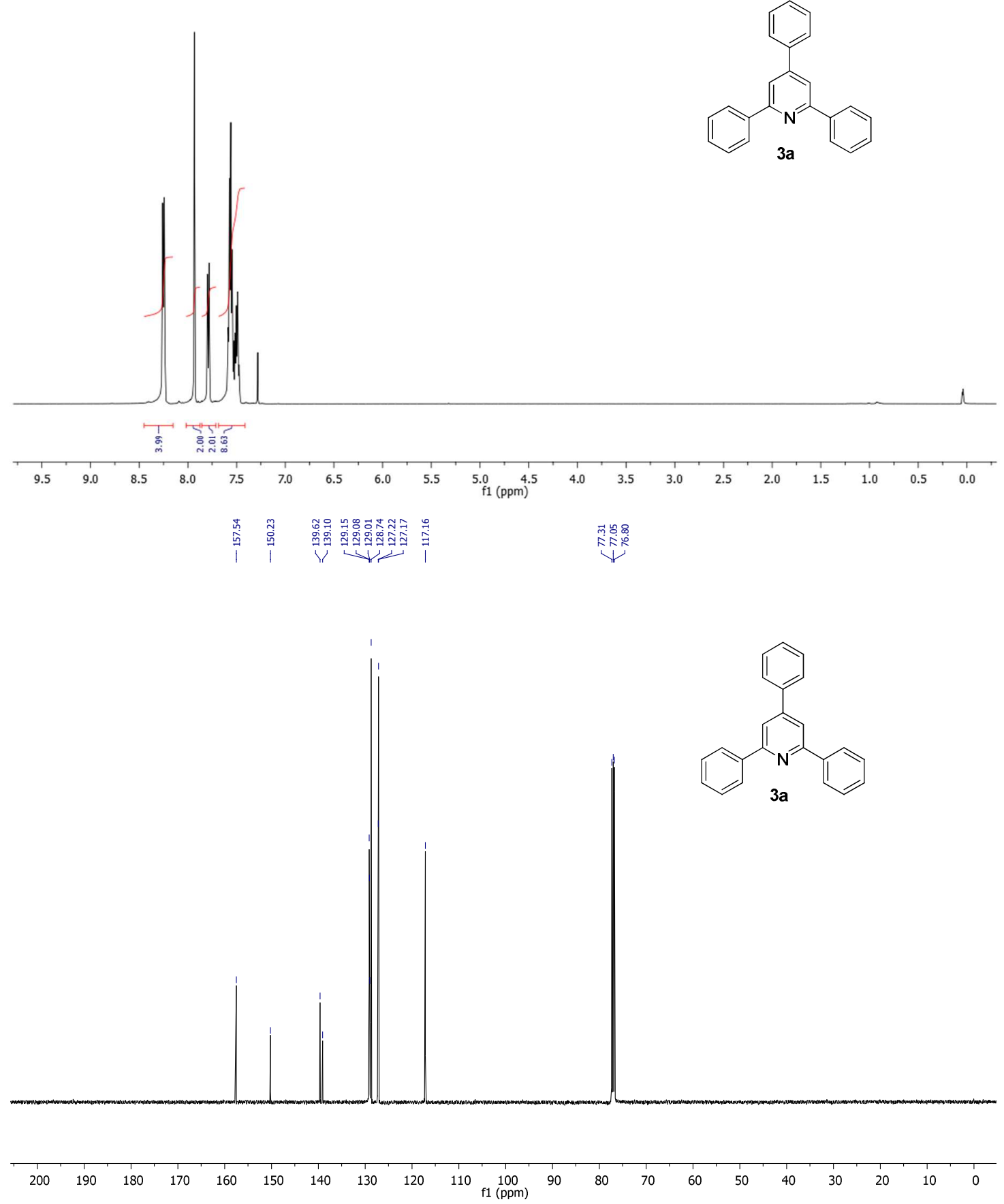


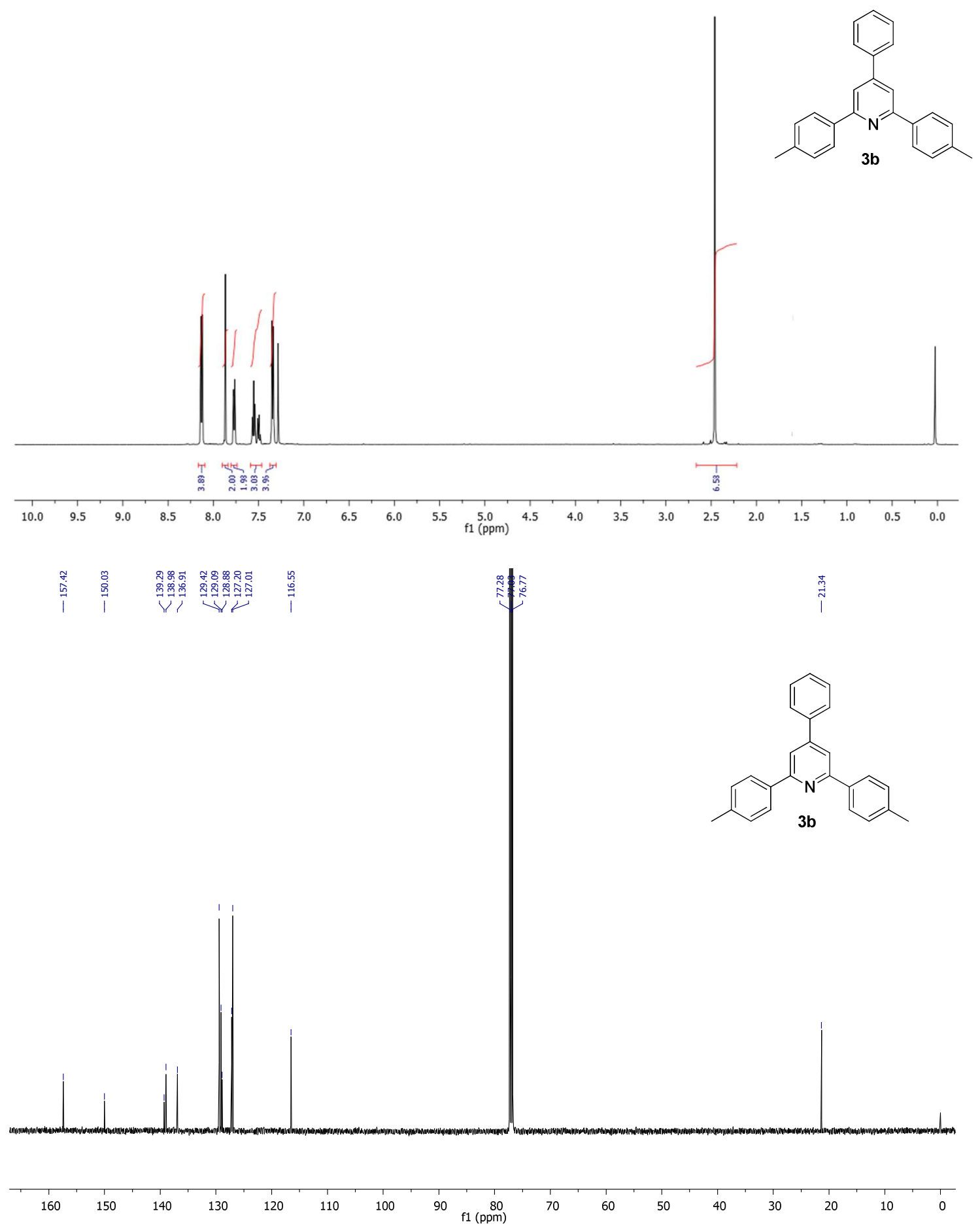




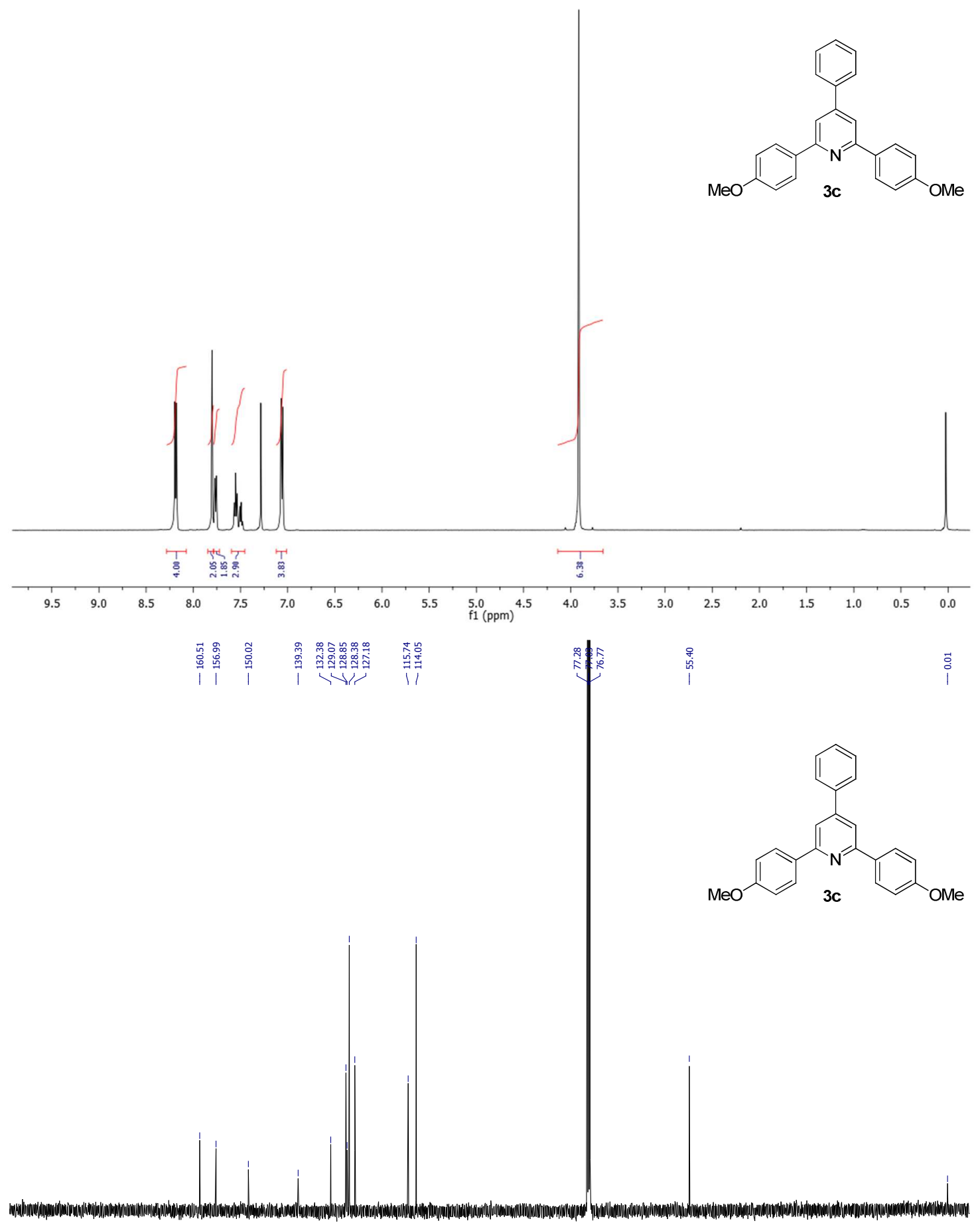

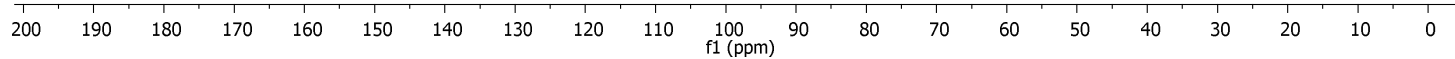



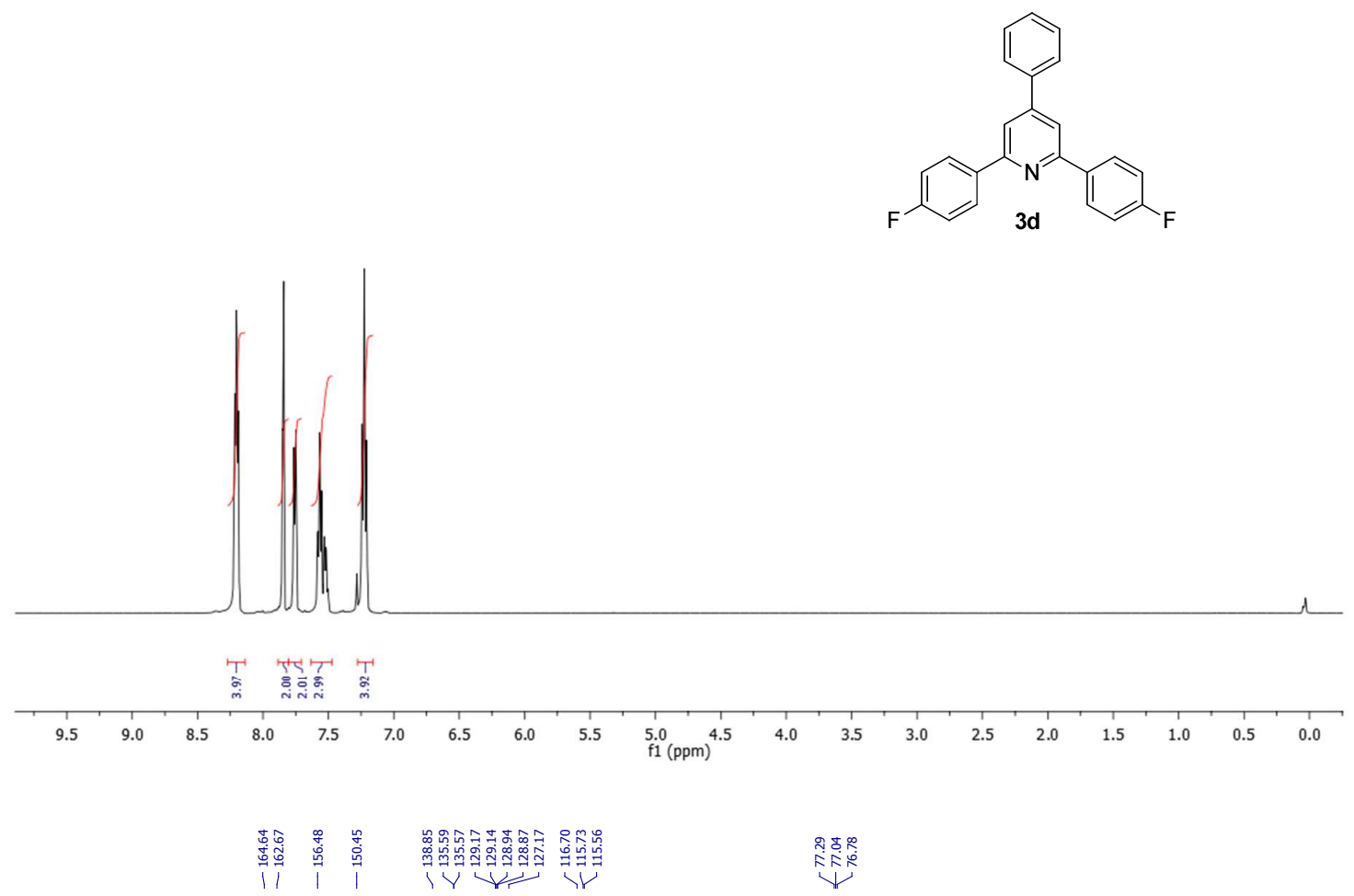

لَ

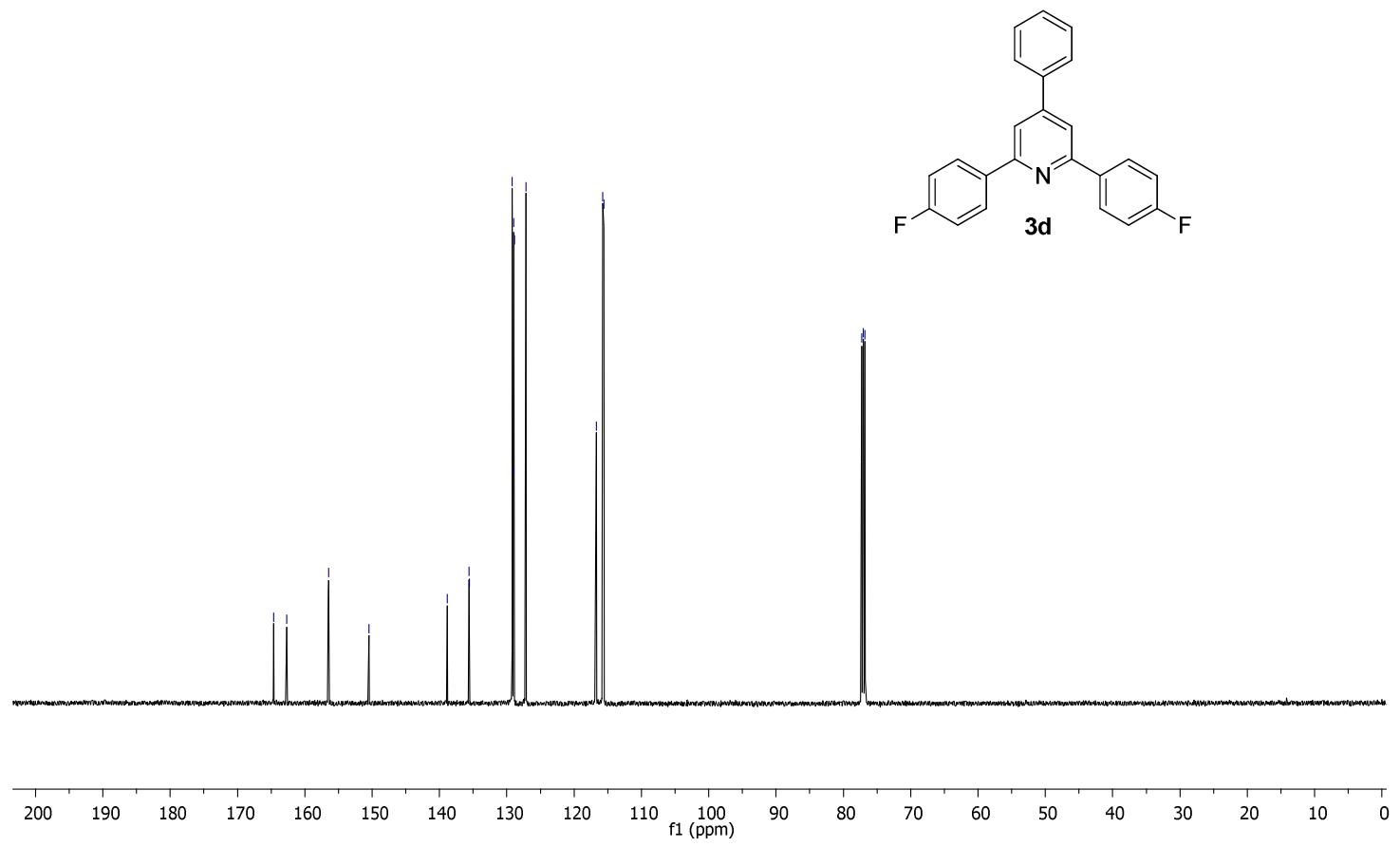



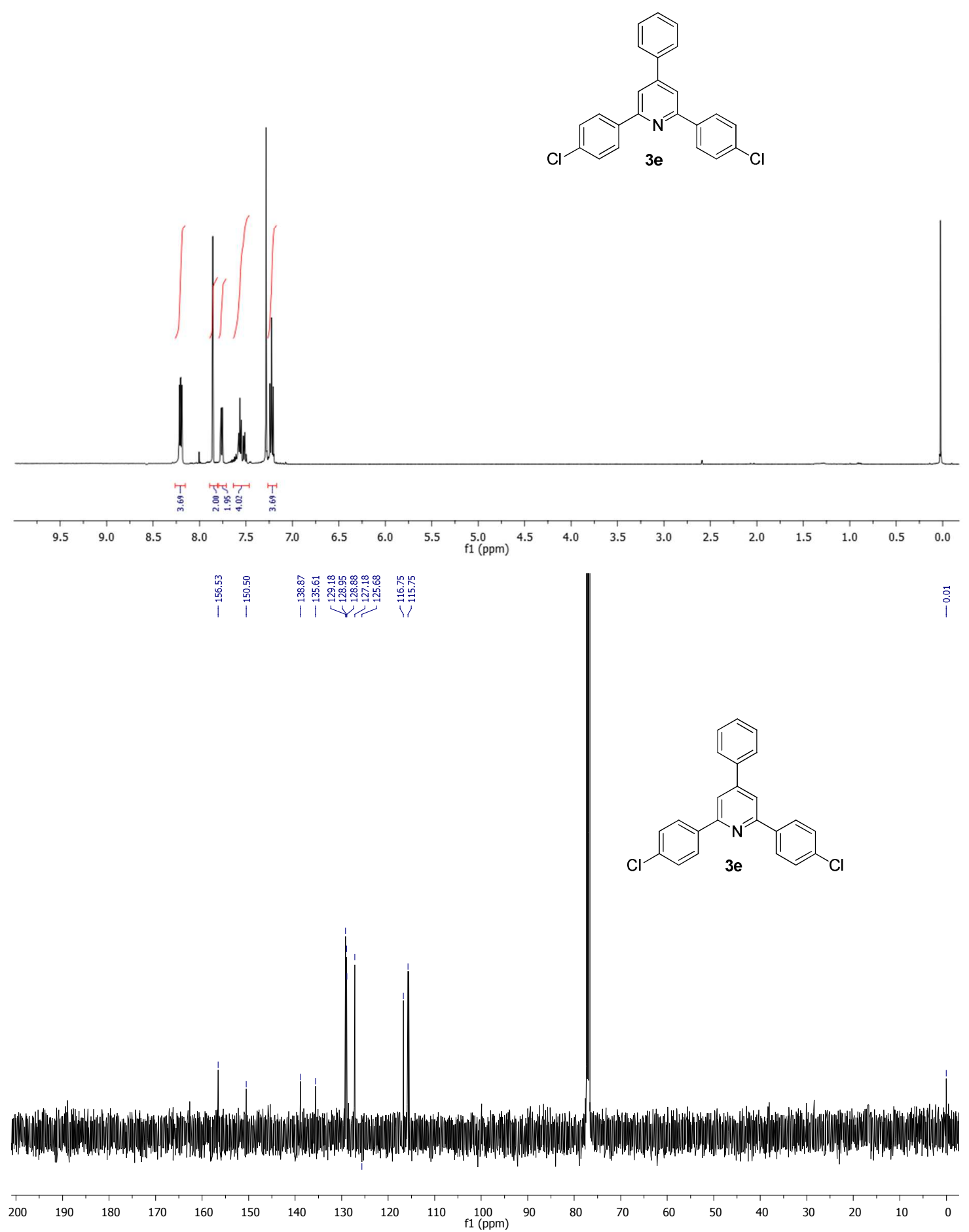

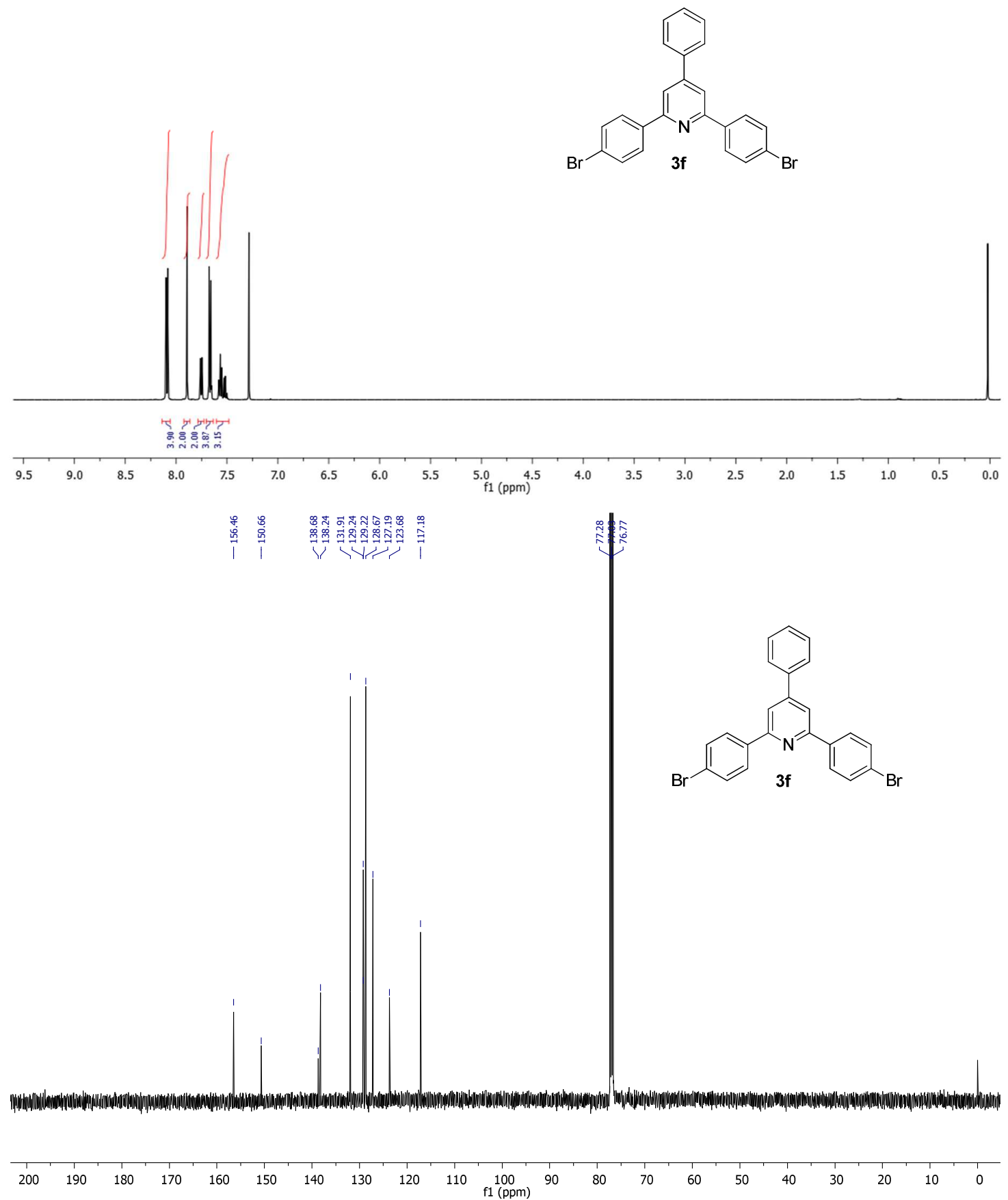

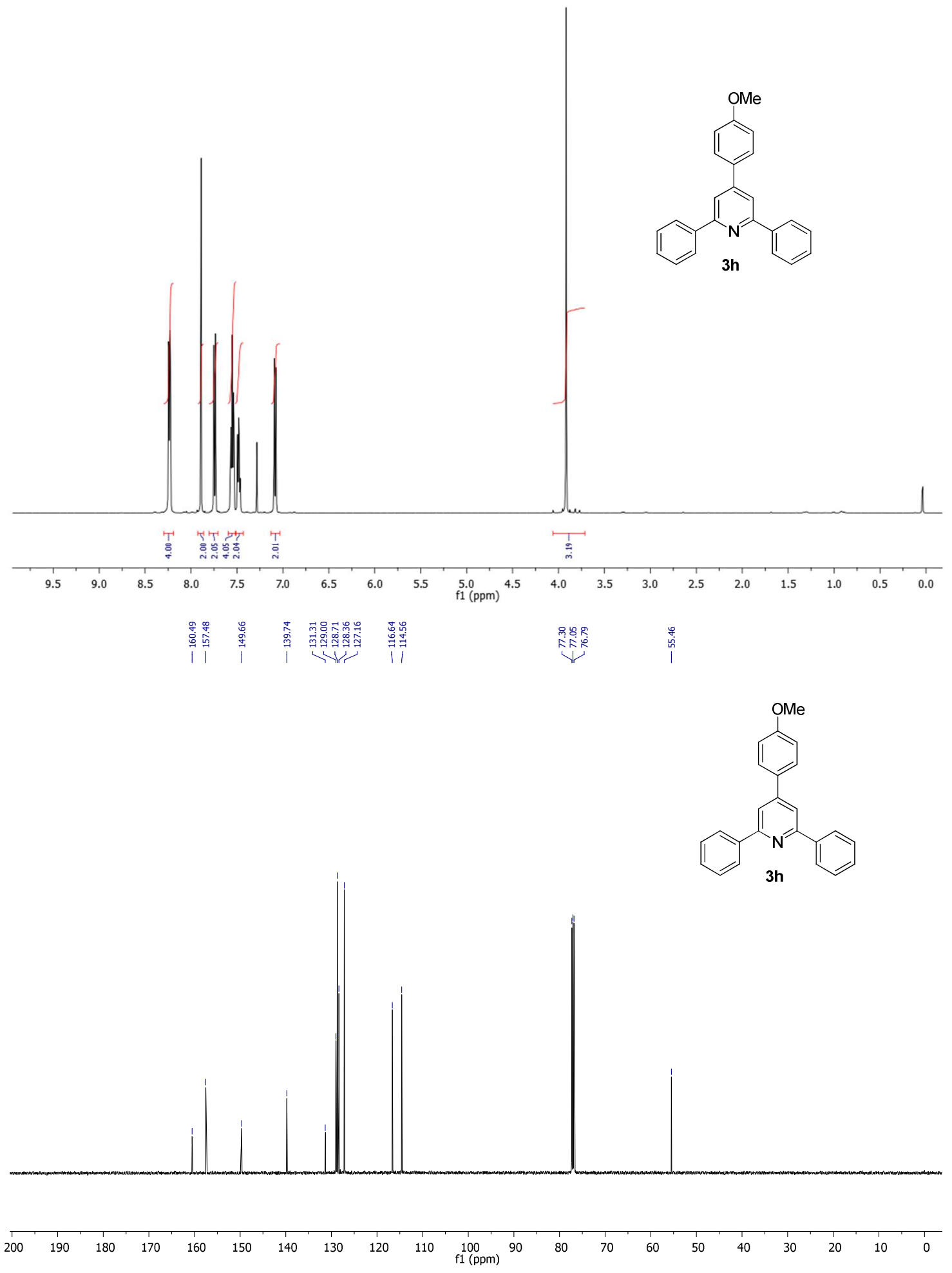


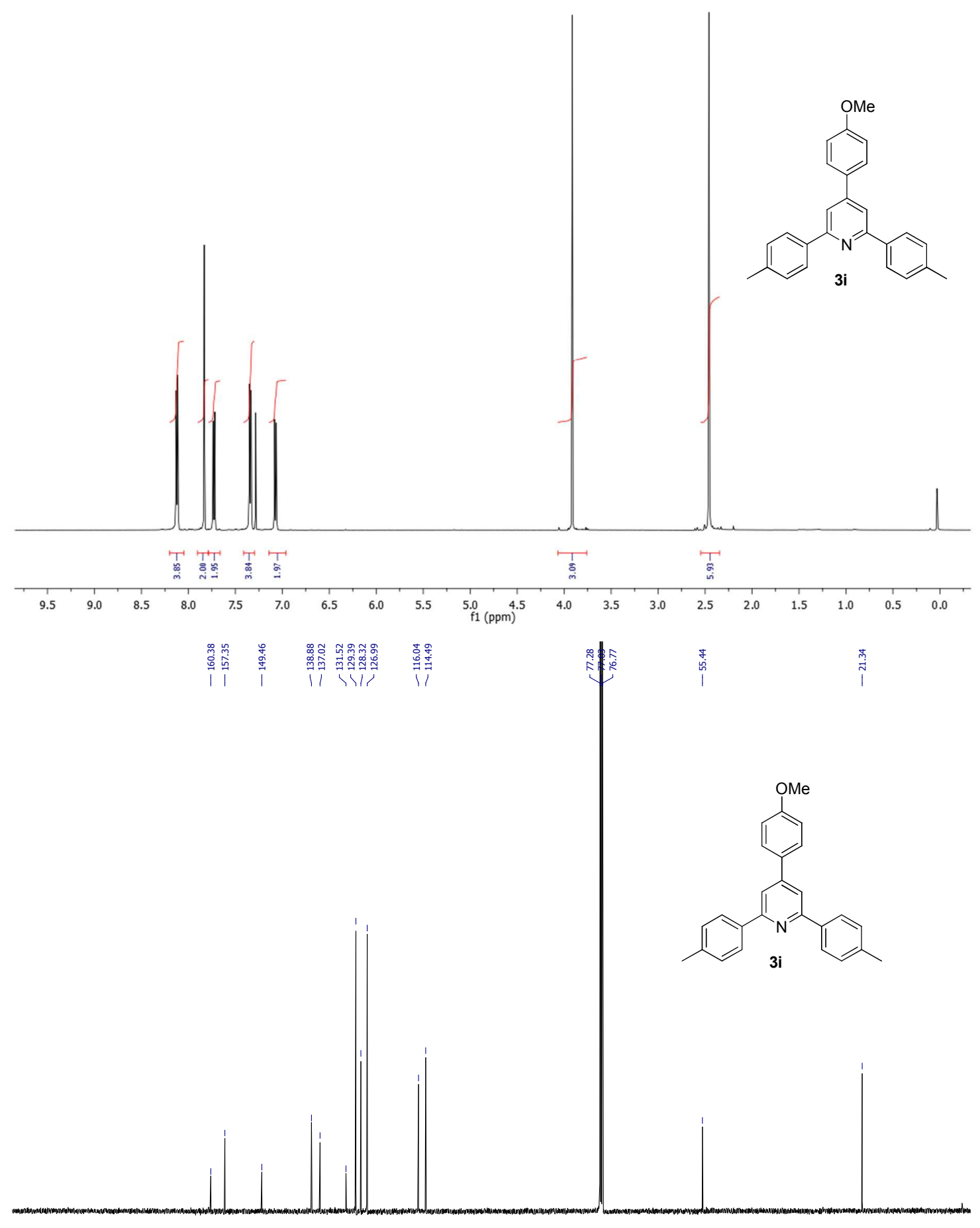

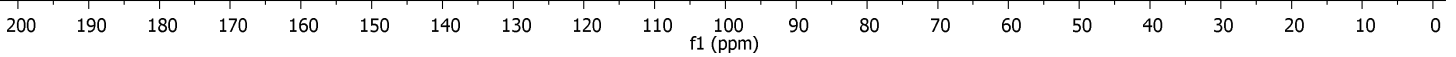




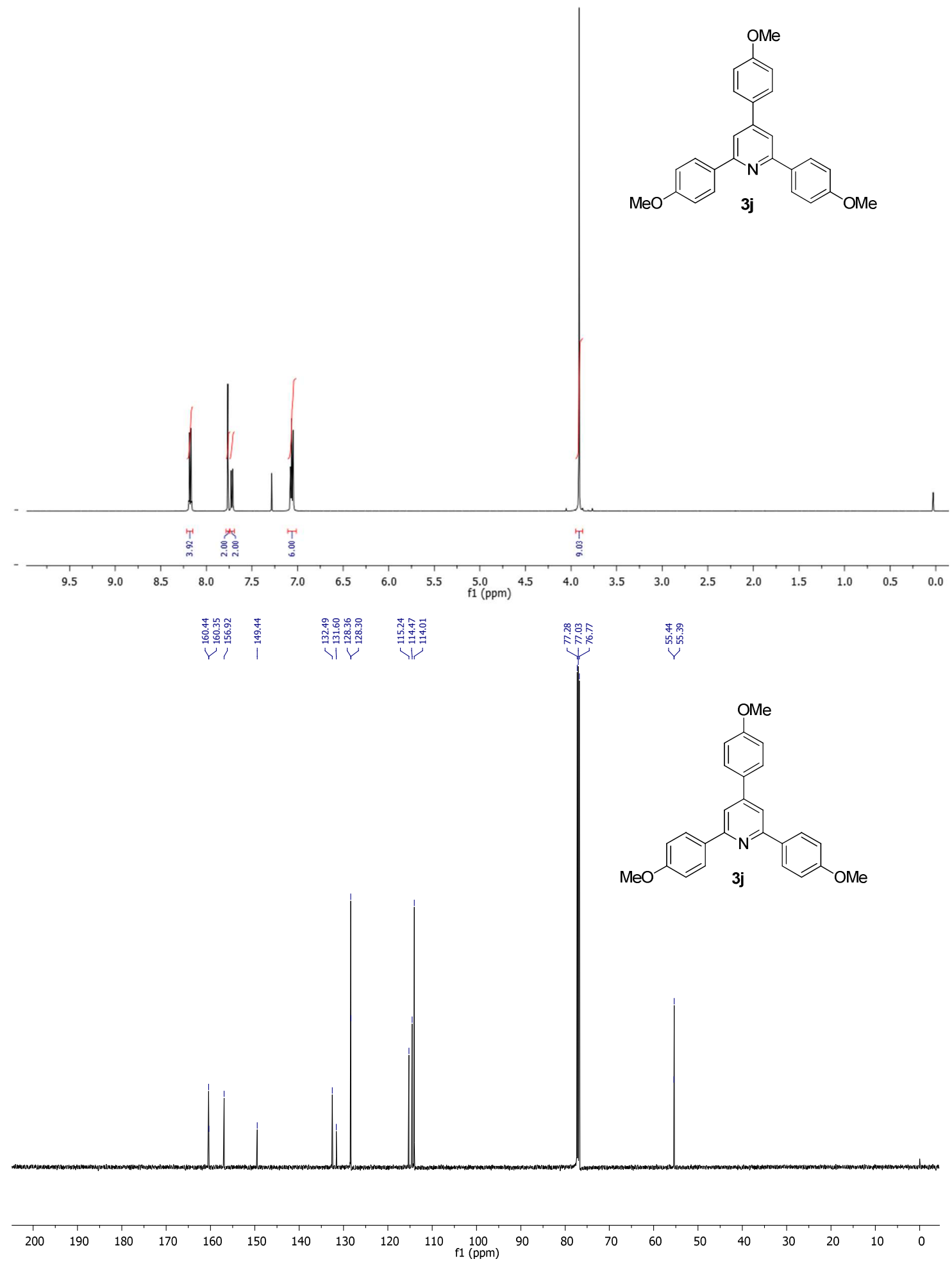



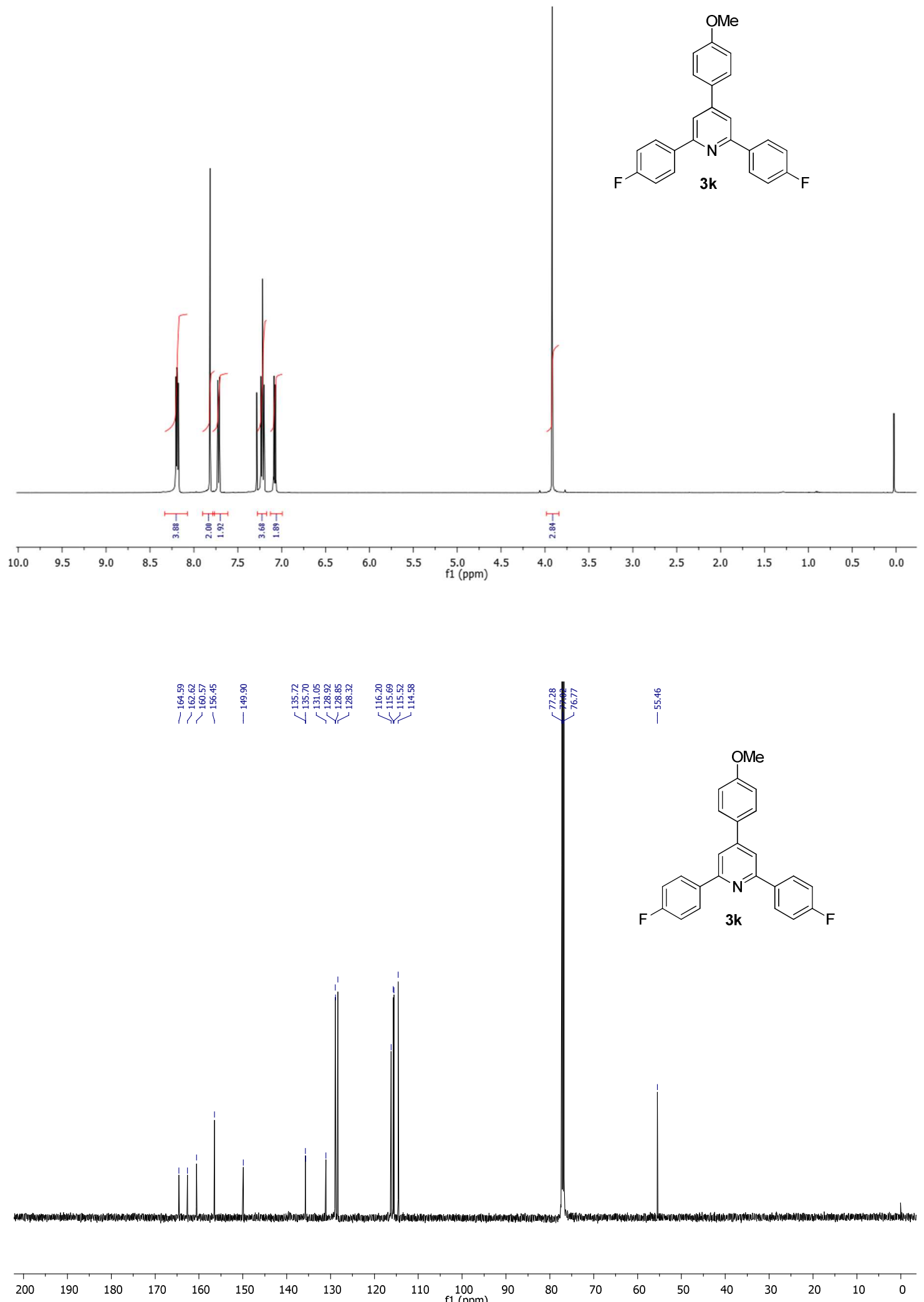

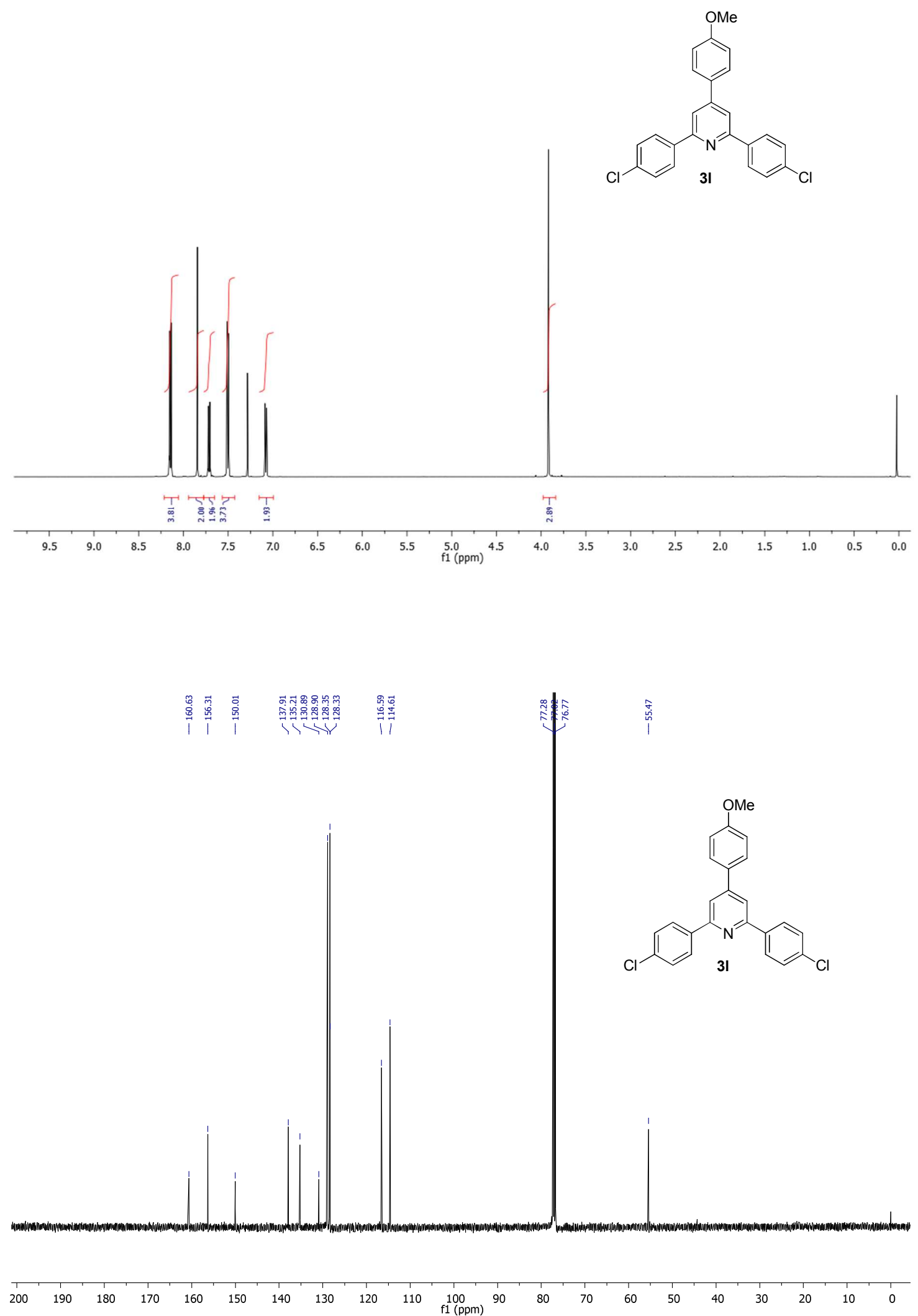

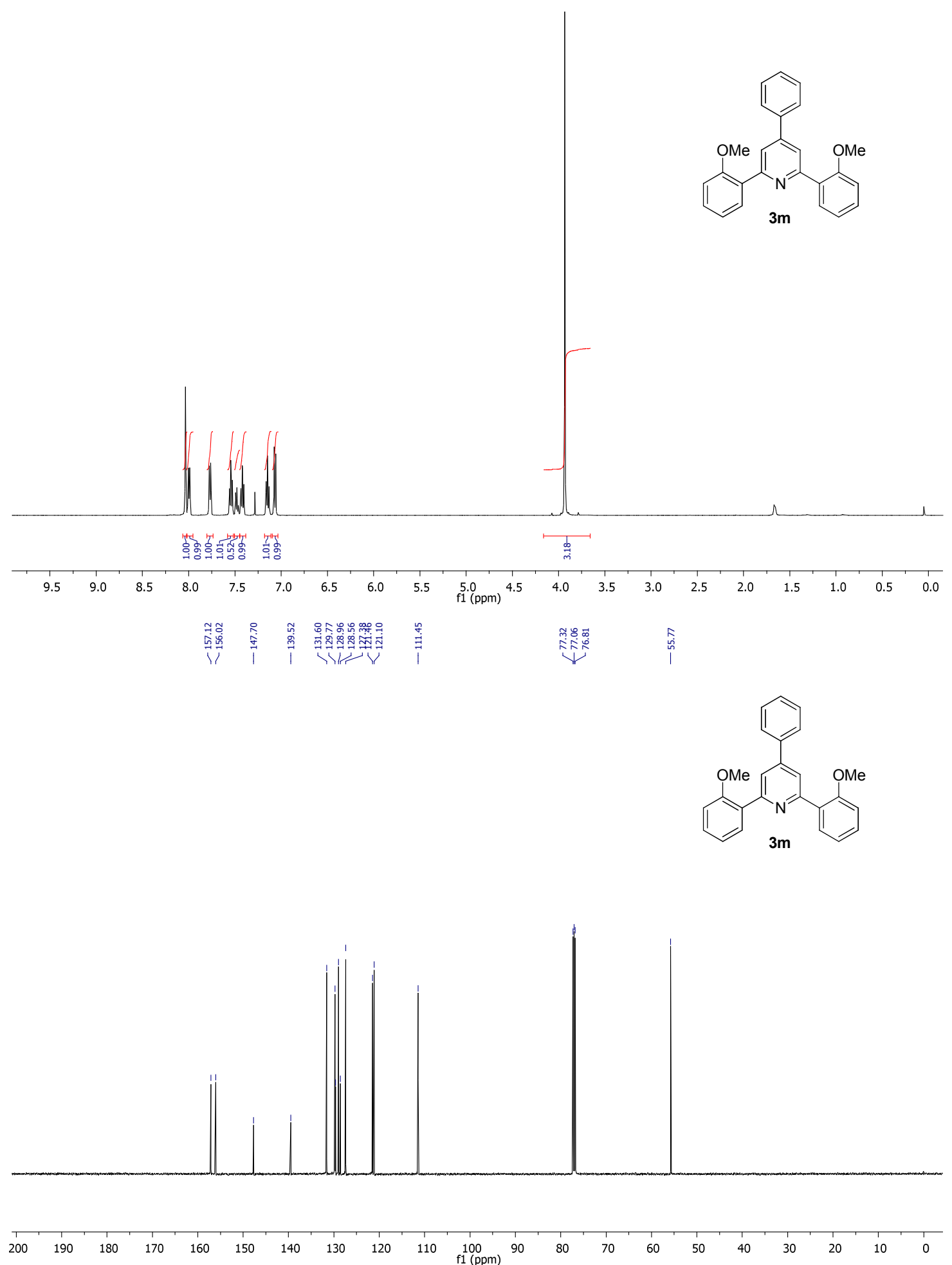

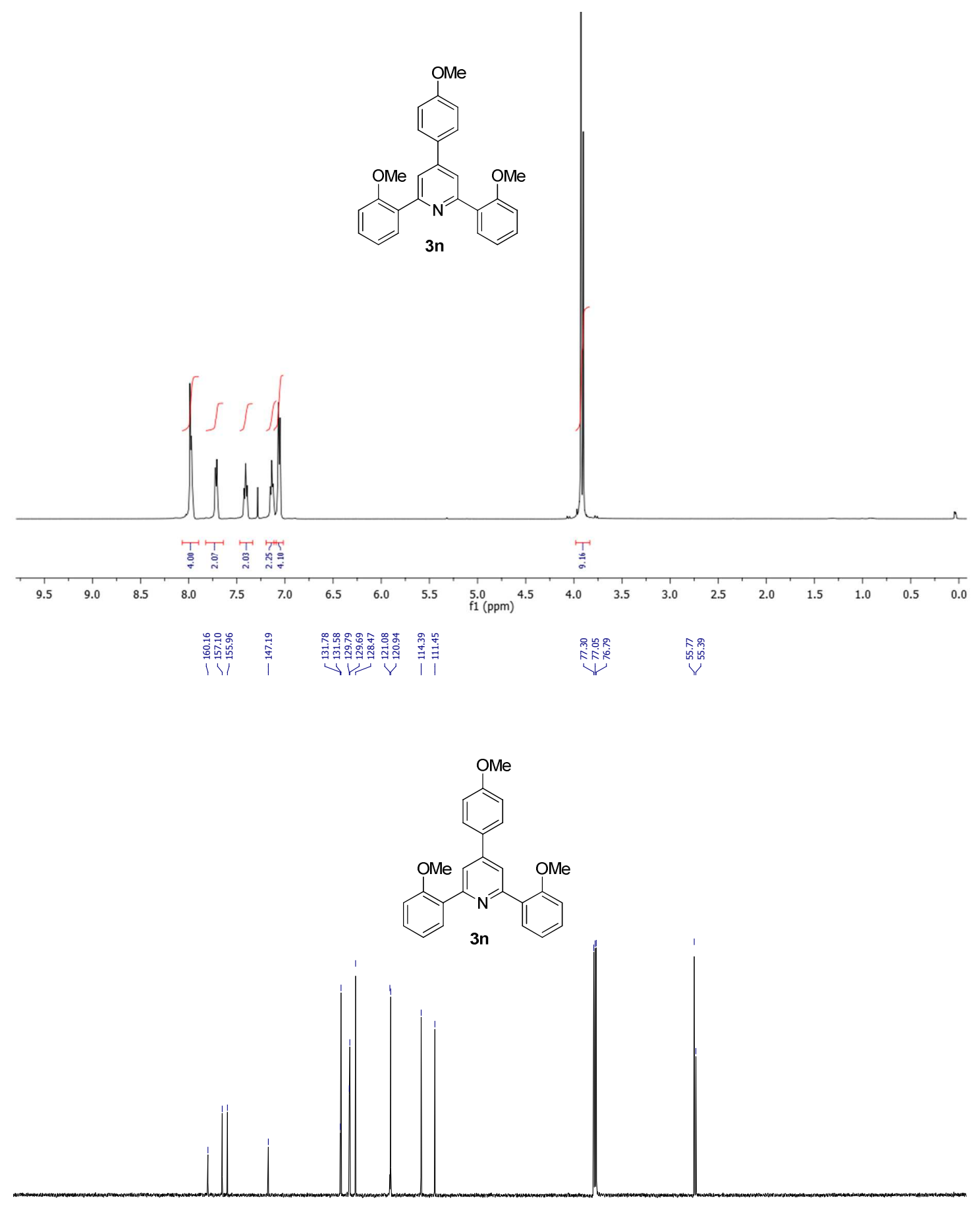

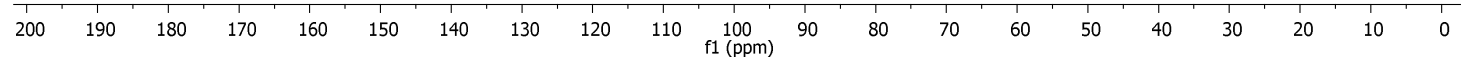




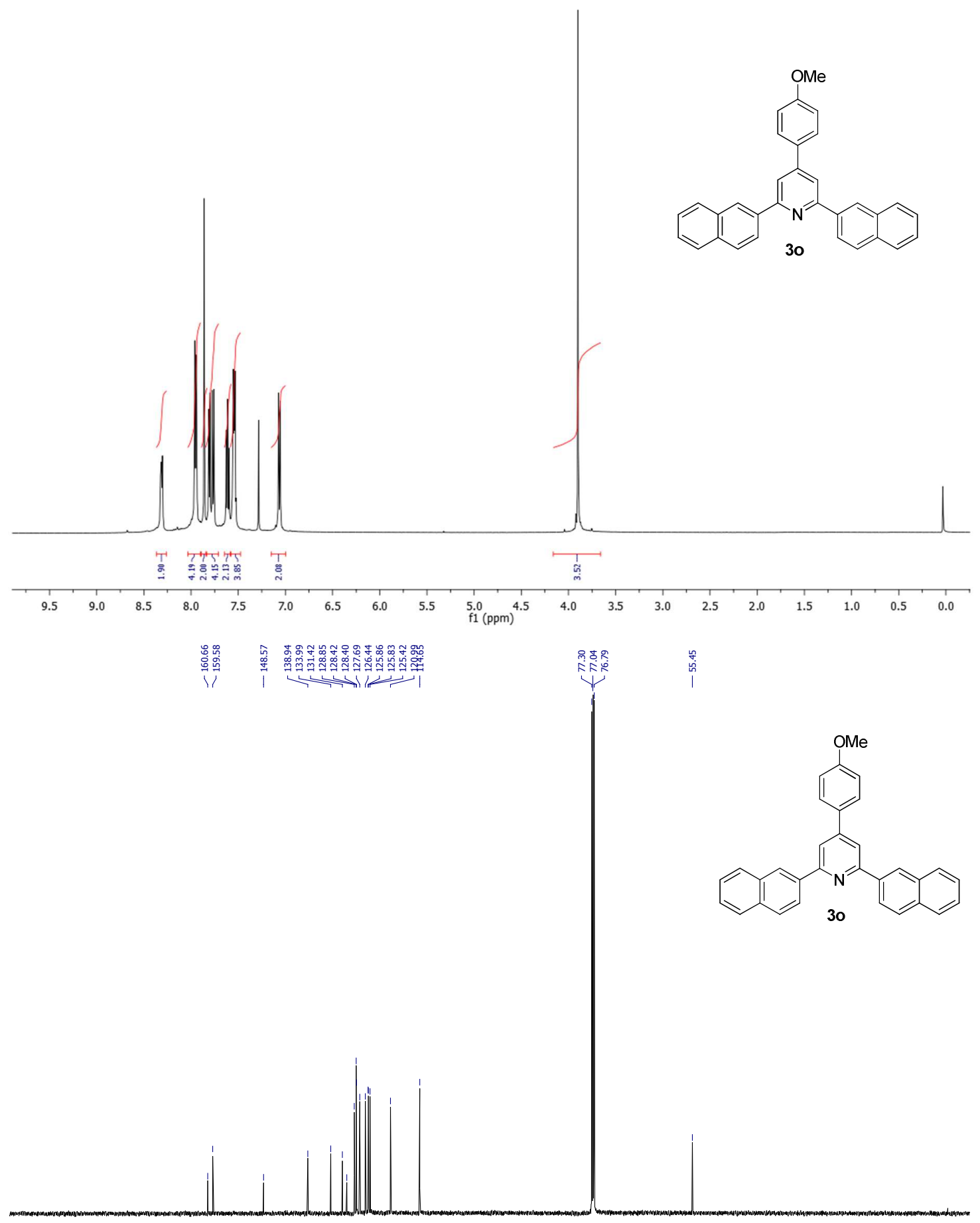

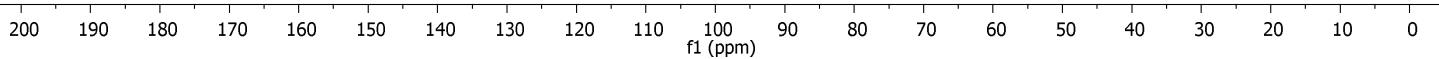



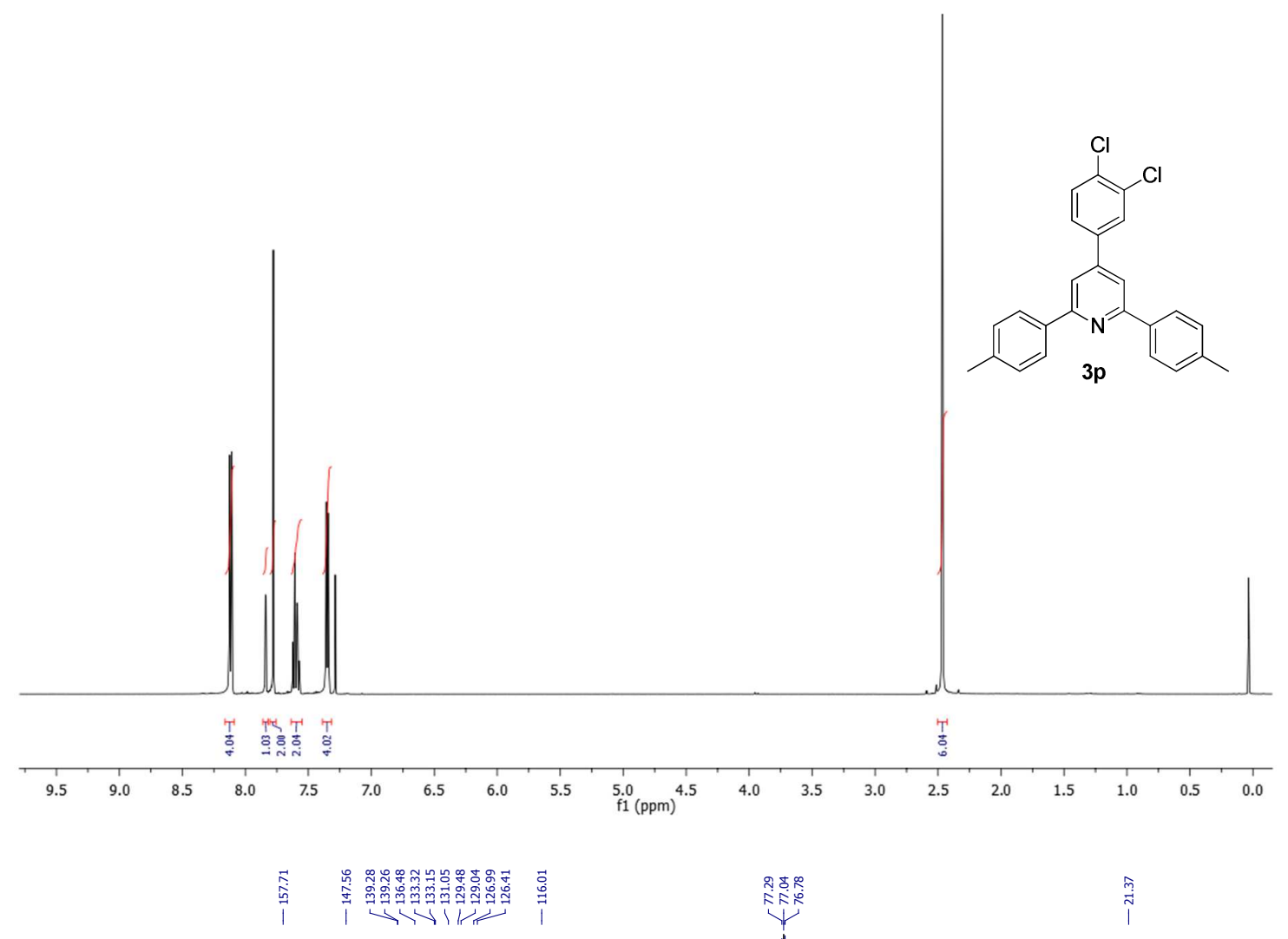

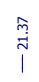
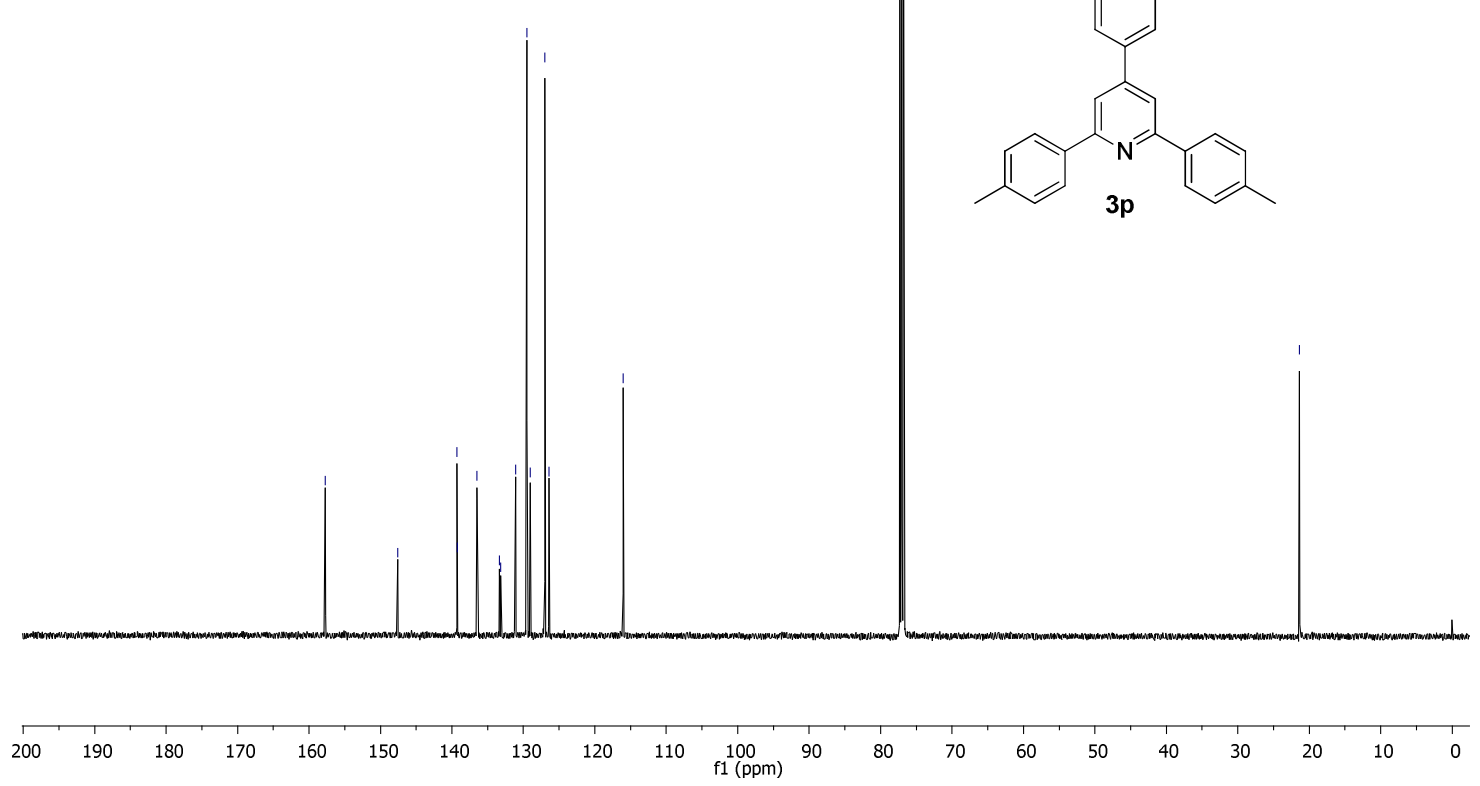

16 

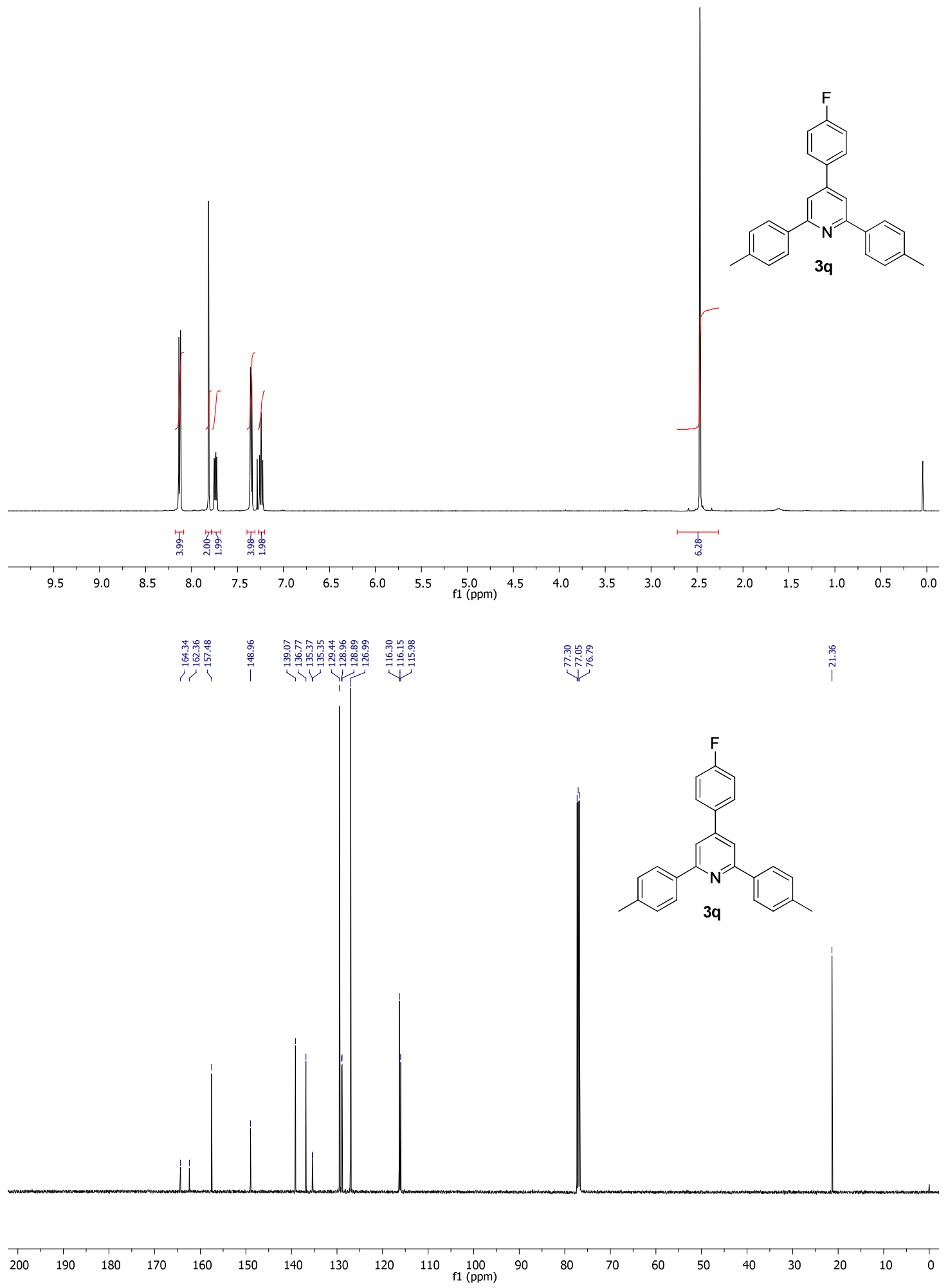

17 

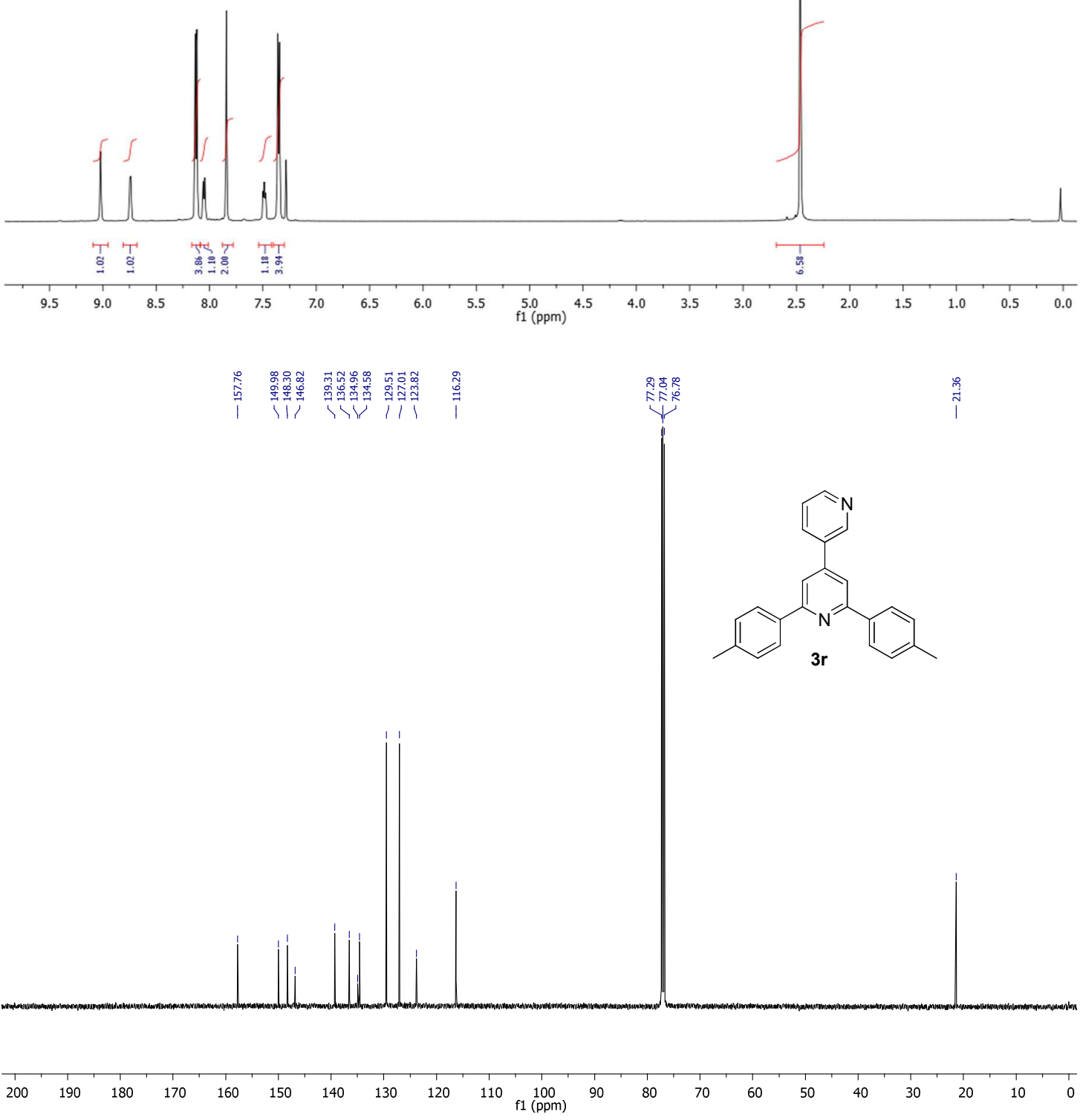

18 

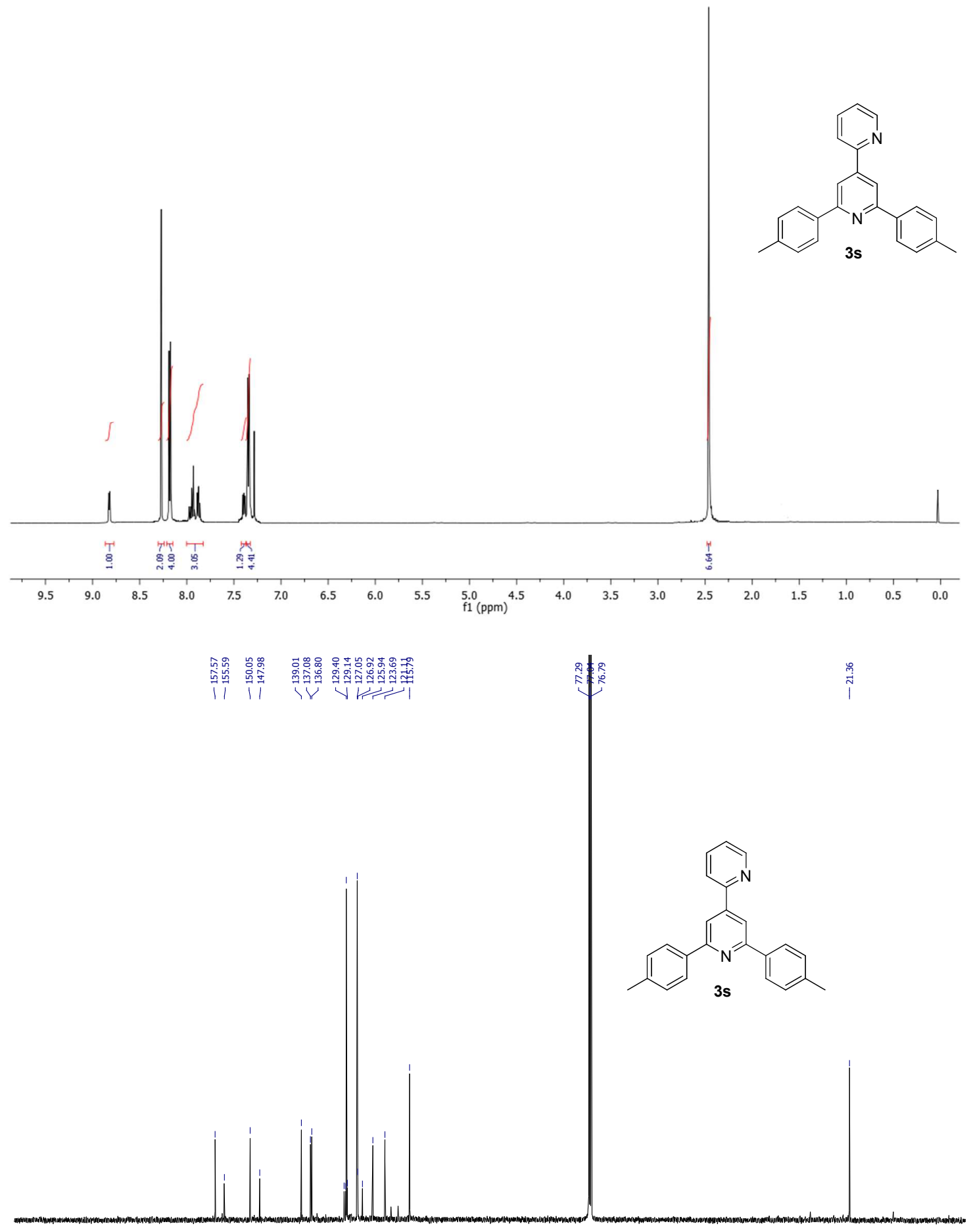

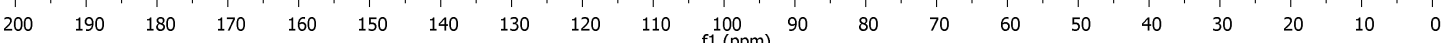



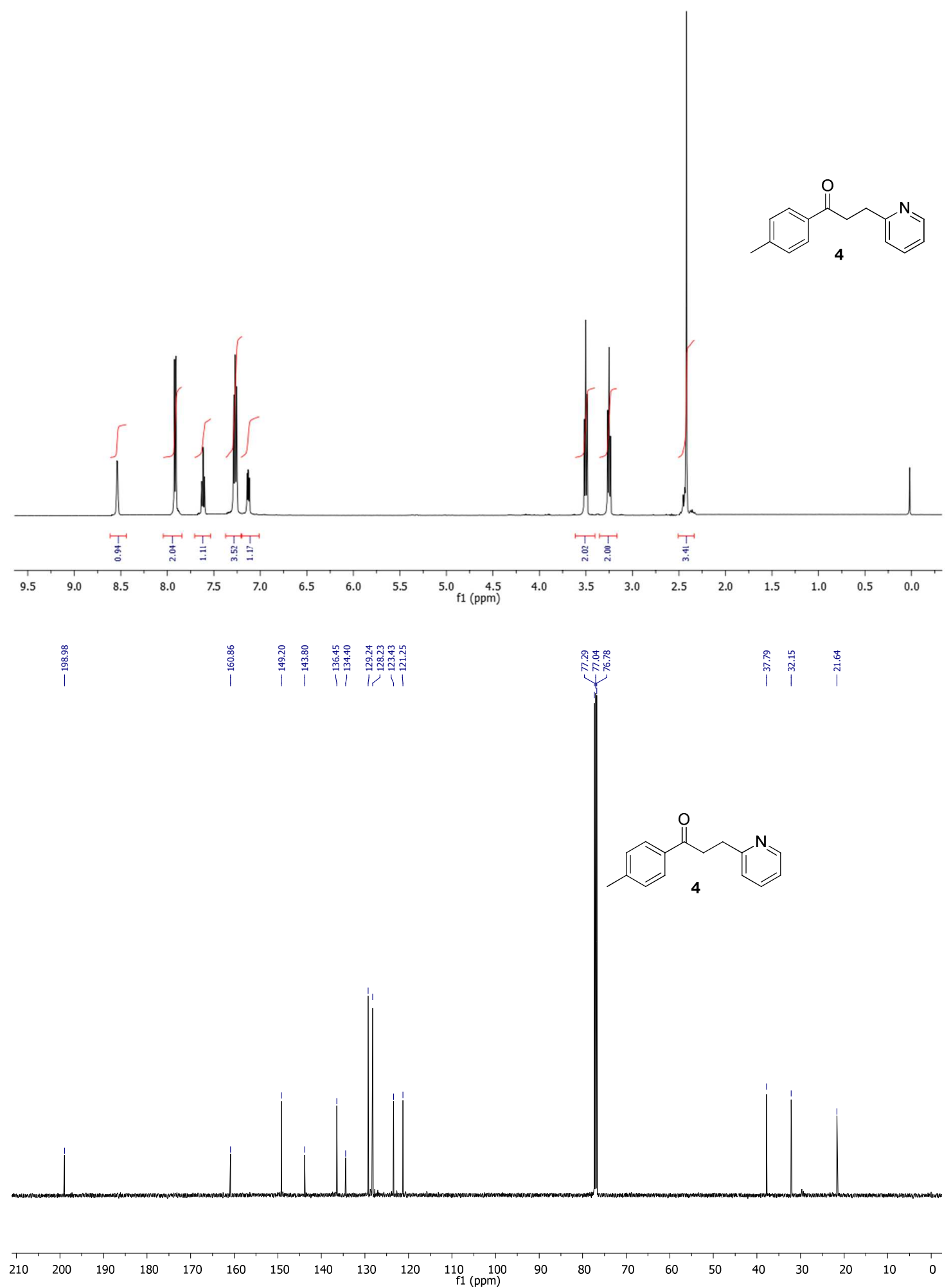

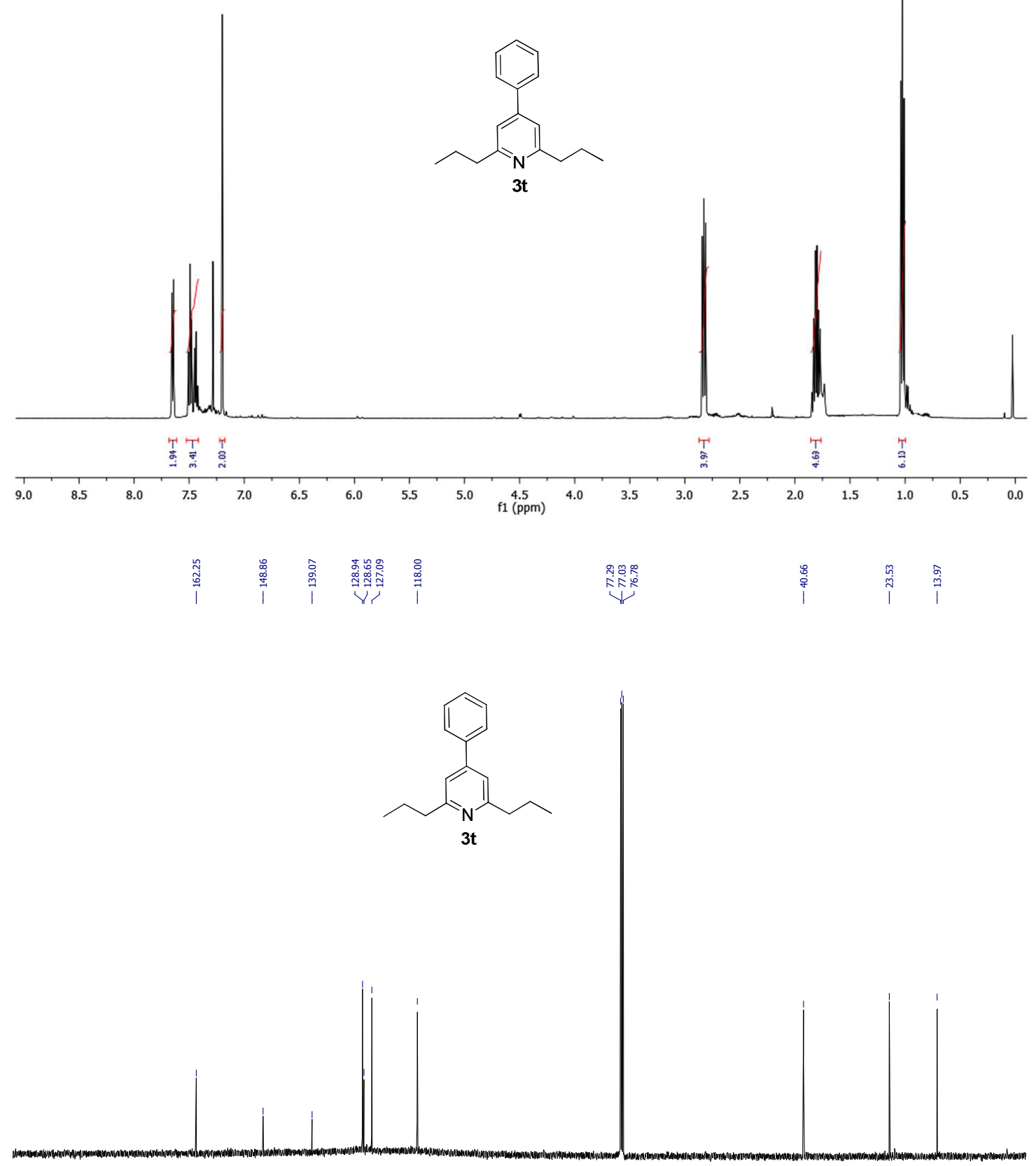
${ }^{1}$ HNMR of crude compound 5

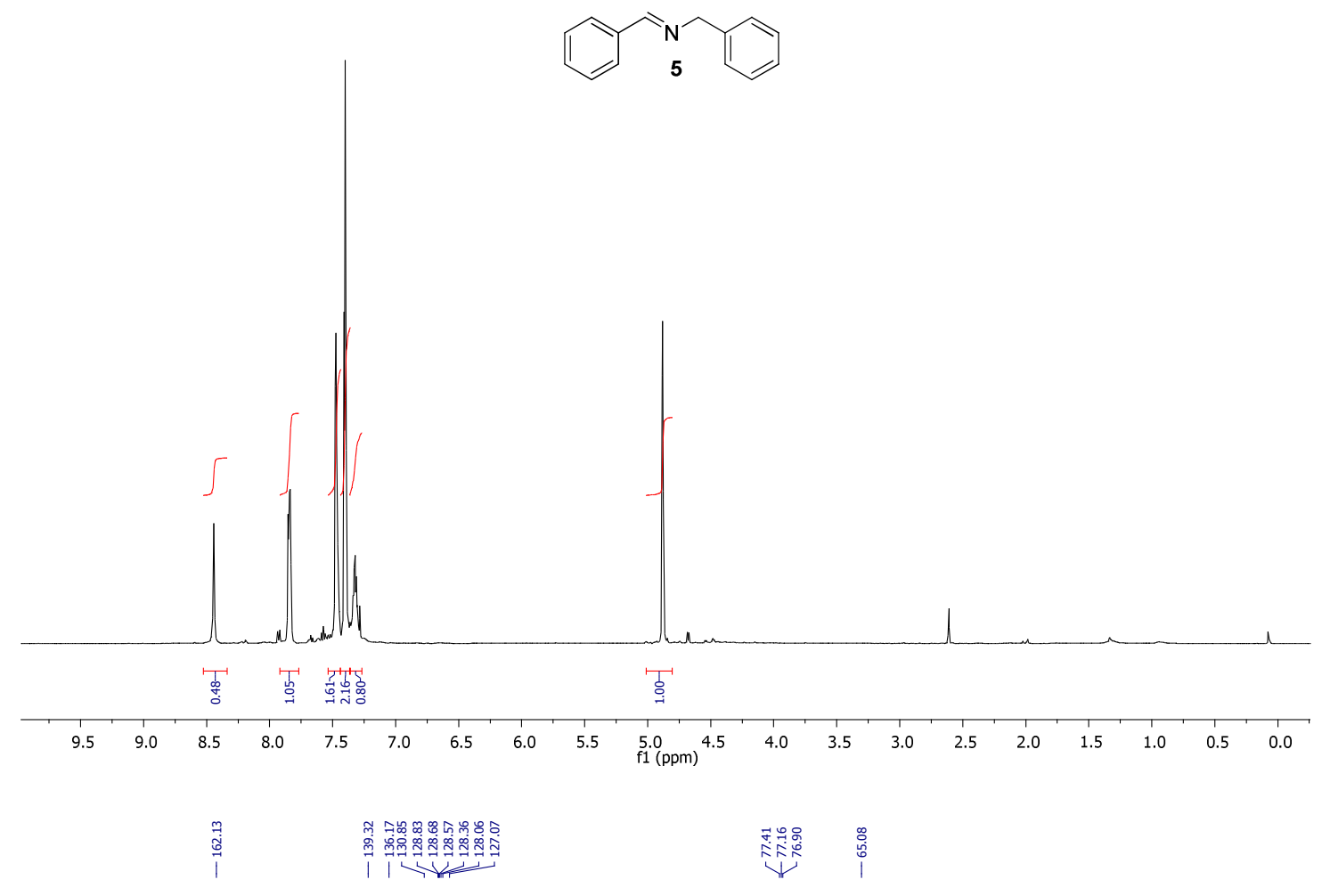

${ }^{13} \mathrm{C}$ NMR of crude compound 5

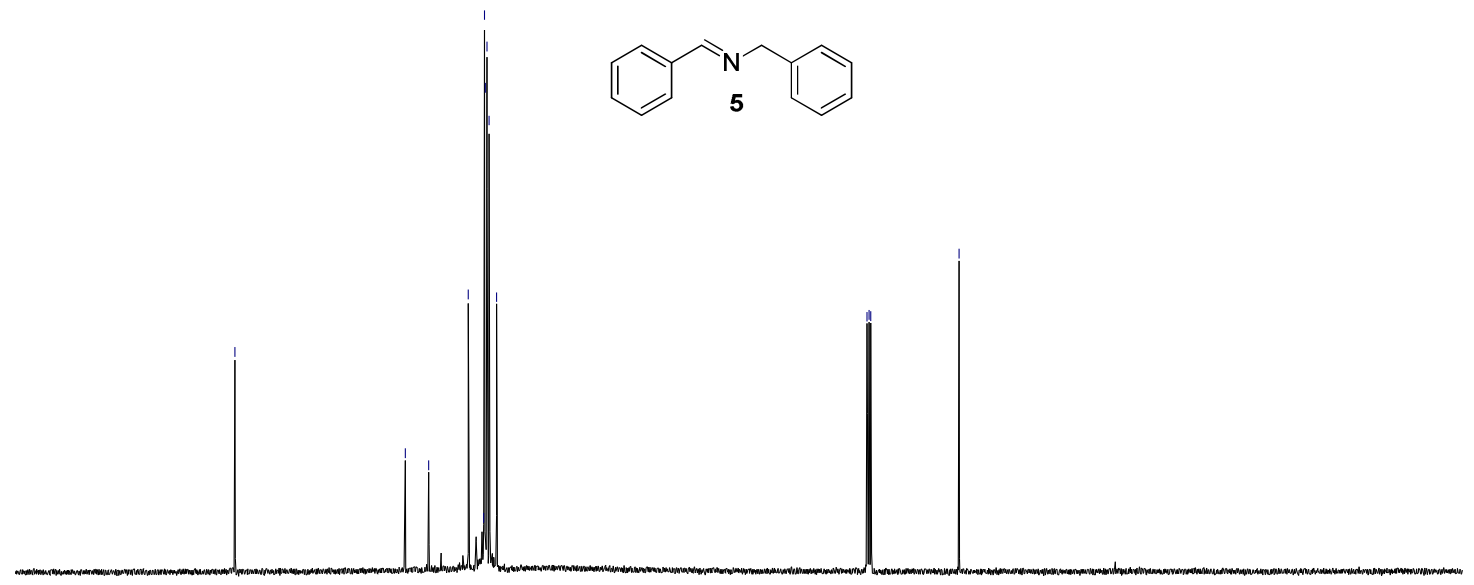

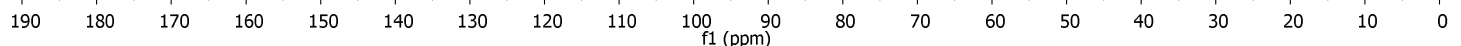




\section{Savitribai Phule Pune University - Central Instrumentation Facility}

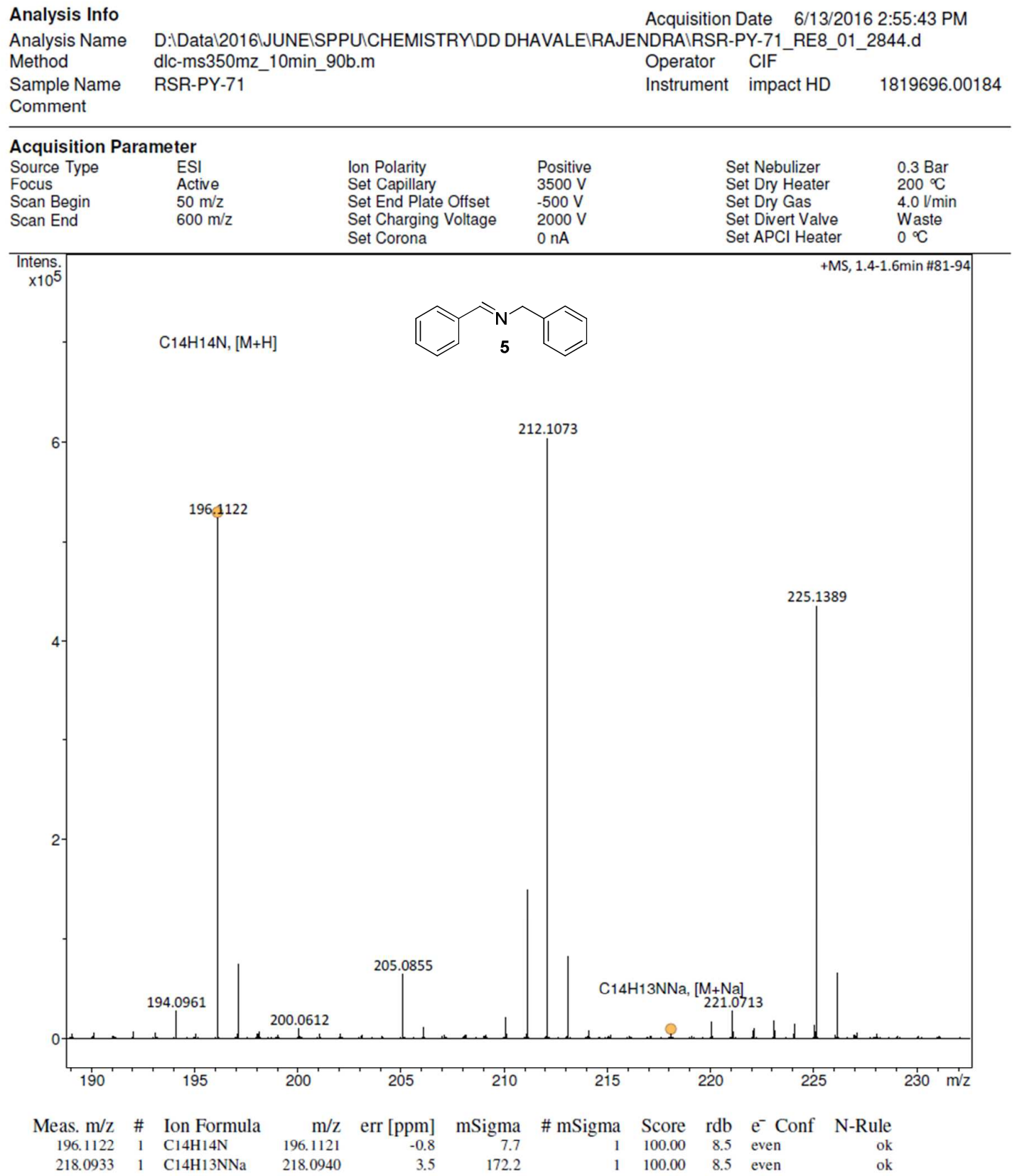

RSR-PY-71_RE8 01_2844.d

Bruker Compass DataAnalysis $4.2 \quad$ printed: 6/13/2016 3:12:48 PM $\quad$ by: CIF 1 